\title{
ŞANLIURFA KALE ETEĞİ NEKROPOLÜ KAYA MEZARLARI
}

\section{ŞANLIURFA CASTLE SKIRT NECROPOLI STONE TOMBS}

\section{СКАЛЬНЫЕ ГРОБНИЦЫ НЕКРОПОЛЯ У ПОДНОЖИЯ КРЕПОСТИ ШАНЛЫУРФА}

\section{Yusuf ALBAYRAK ${ }^{*}$}

\section{ÖZ}

Şanlıurfa şehir merkezinde bulunan ve bugün Şanlıurfa Kalesi olarak adlandırılan kalenin eteğinde bir Nekropol alanı bulunmaktadır. Son yıllarda yapılan kazı ve temizlik çalışmalarında Nekropol alanında bulunan tüm kaya mezarları ortaya çıkarılmıştır. Roma kaya mezar mimarisini yansıtan mezarlardan günümüze koruna gelenler detaylı şekilde incelenmiş ve tipolojileri çıkarılmıştır. Buna göre de buradaki mezarlar sınıflandırılmıştır; Merdivenli veya rampalı Dromoslu tek odalı ve üç Arcaseliumlu kaya mezarları, basit girişli tek odalı ve üç Arcaseliumlu kaya mezarları, geçişli iki odalı ve beş Arcaseliumlu kaya mezarları ve Loculuslu mezar odalı kaya mezarları.

Anahtar Kelimeler: Kaya Mezar1, Dromos, Arcaselium

\section{ABSTRACT}

There is a necropolis area in the city center of Şanliurfa and today it is called Şanliurfa Castle. In recent years, excavations and cleaning work have revealed all rock tombs in the Necropolis area. From the graves reflecting the Roman rock tomb architecture, the details of the day-to-day survivals were studied in detail and the typologies were removed. According to this, the graves were classified here; Oneroom and three-arcaselium rock tombs with stairs or ramps, one-roomed with simple entrance and three Arcaselium rock tombs, two-roomed rock-cut tombs with five interlocking Arcaseliums and rock tombs with Loculus tombs.

Key Words: Rock Tomb, Dromos, Arcaselium

\section{АННОТАЦИЯ}

В центре города Шанлыурфы расположена крепость, у подножия которой находится Некрополь (город мертвых). В результате проведенных в последнее время раскопок обнаружены места скальных гробниц в Некрополе. Исследования показали, что в них сохранились традиционные архитектурные оттенки Римской скальной гробницы. На основе этого гробницы

* Harran Üniversitesi, Fen Edebiyat Fakültesi, Arkeoloji Bölümü, Osmanbey Kampüsü, ŞANLIURFA, E-posta: albayrakyusuf55@hotmail.com

10.17498/kdeniz.366359 
подразделяются: лестничные или ярусные дромосы с одной и тремя аркосолиумы скальные гробницы; обычные однокомнатные и трехкомнатные аркосолиумы скальные гробницы, временные двух и пятикомнатные аркосолиумы скальные гробницы и отдельные комнаты скальных гробниц локулус.

Ключевые слова: скальные гробницы, дромос, аркосолиум.

\section{Giriş}

İnsanoğlu yaşamla ilgili tüm olguları benimsemesine rağmen ölümü kolayca kabullenememiştir. Fakat kaçınılmaz olan ölüm toplumlarda her şeyin sonu olarak algılanmamıştır. Ölümden sonraki yaşama ilişkin inançlar, insanoğlunun ölüleri için mezar yapmak fikrini doğurmuştur (Seeher 1993, 9; Özgüç 1948, 98). Ölülerin gömülmesi işlemi farklı yöntemlerle günümüze kadar uygulana gelmiştir. $\mathrm{Bu}$ yöntemler: Yeraltı oyma mezarlar, yeraltı örme mezarlar, yeraltı oyma - örme mezarlar, taş sandık mezarlar, toprak mezarlar, urneler, küp mezarlar, kaya mezarlar (Çevik 2000, 8), ve taş tekneler; yani lahitlerdir (Koch 2001, 1). Kaya mezar odaları kişinin bir sonraki yaşamını devam ettireceği alanlar olarak düşünülmüş ve bir konuta benzetilmiştir. Kaya işleme sanatı Anadolu'da Hititler döneminde dinsel, fakat genelde politik amaçlı kabartmalarla başlar ve tarihin akışı içinde boyut kazanarak Erken Hıristiyanlık Kapadokya'sında kaya kentlerine dönüşür (Sivas 1999, 201). Kayaya mezar açma geleneği ise ilk olarak M.Ö. 9. yüzyılda Urartular'la başlar (Işık 1989, 17). Olasılıkla Persler'in Anadolu'ya gelişleriyle de M.Ö. 6. yüzyılın 2. yarısından itibaren yaygınlaşır (Kurt ve Boardman 1971, 325). Kuzey Suriye'de yaygın olan (Orthmann 1979,101) yer altına veya yer üstüne taş duvarlarla yapılanların yanı sıra kayalara oyularak da elde edilmiş oda mezarlar Anadolu'nun Güneydoğu kesimini de oldukça çok etkilemiştir (Ensert 1995, 171).

Antik Çağ şehirlerinin önemli bir öğesi de Nekropollerdir. Ölüm sonrası başka yaşam inancı, nekropollerin, özellikle Roma Döneminde yaygınlaşan anıtsal mezar yapılarını da içeren çok çeşitli mezarlarla donatılmasına yol açmıştır ve bunlar ölülere ait kutsal şehir gibi düşünülmüşlerdir. Nekropoller, hem kapladıkları geniş alanlar, hem de sağlık ve dinsel sebeplerden dolayı genellikle şehir surlarının dışında gelişmişlerdir (Cormack 1997, 140).

Nekropollerde kaya mezarları oldukça yaygındır. Kaya mezarlarını, kaya oyuğu ya da kaya aralığı mezarları (Turani 1993, 67), yerli büyük kaya kitlelerinin tabii oyuk ve aralıkları ile ana kayaya direkt oyularak yapılan mezarlar olarak tanımlayabiliriz (Özgüç 1948, 14). Mezar odası girişleri açısından düz, kuyu biçimli, rampalı ve merdivenli girişler gibi farklılıklar, tek-ikili-çok odalı plan tipleri gösterse de genel yapısı ve kullanışındaki amaç açısında belirli bir bütünlük göstermektedir (Orthmann 1979,101). Anadolu'da yapılan kaya oyulmuş oda mezar türü zenginlik ve gösteriş kaygısı taşıdığından özellikle Roma Çağında çok kullanılmıştır (Mansel 1971, 542-544).

Kale Eteği Nekropolü olarak adlandırılan alan, bugün Şanlıurfa İli merkezinde bulunan ve Urfa kalesi olarak bilinen kalenin surlarının bittiği güney 
batı kısmındadır. 2012 yılına kadar bir gece kondu mahallesi olan Nekropol alanı, yol çalışmaları sırasında kaya mezarlarının bulunması ile dikkat çekmiştir. Nekropol alanındaki kaya mezarlarını ortaya çıkarmak için Şanlıurfa Müzesi başkanlığında ve benim bilimsel danışmanlığımda 2015 yılında başlatılan kazılar 2017 yılında sona ermiştir. Çalışmalar sonrasında toplamda 72 tane kaya mezarı ortaya çıkarılmıştır. Mezarların tepeden aşağı doğru, üç teras şeklinde, kuzey doğudan güney batı hattı üzerinde, yan yana sıralandıklarını görmekteyiz (Resim 12). Bu mezarlardan 44 tanesi az bir tahribat ile günümüze koruna gelmiş, 28 tanesi ise kaya mezarı özelliğini tamamen yitirmiştir. Koruna gelen mezarlardan Dromos merdivenleri tahrip olanlar, M-5, M-8, M-24, M-26, M-27, M-28, M-52, M-56, M60, girişi tahrip olanlar M-9, M-11, M-16, M-17, M-20, M- 21, M-23, M-29, M-32, M-34, M-54, M-56, M-58, M-59, M-65, M- 69, bir ya da daha fazla Arcaseliumu tahrip olanlar, M-7, M-8, M- 19, M-22, M-23, M-26, M- 28, M- 41, M-58, M-65, M-74 nolu mezarlardır.

Koruna gelen bu 44 kaya mezarına göre, Kale Eteği Nekropolü kaya mezarlarını, merdivenli veya rampalı Dromoslu tek odalı ve üç Arcaseliumlu kaya mezarları (Resim 3), basit girişli tek odalı ve üç Arcaseliumlu kaya mezarları (Resim 4), geçişli iki odalı ve beş Arcaseliumlu kaya mezarları (Resim 5) ve Loculuslu mezar odalı kaya mezarları (Resim 6) olmak üzere sınıflandırabiliriz.

\section{Dromoslu merdivenli ve rampalı tek odalı kaya mezarları}

Yer altına açılan kaya mezarlarına ulaşmak için oluşturulan koridor olan Dromoslar (407) merdivenli ve merdivensiz yapılmıştır. Merdivenli olarak yapılan dromoslarda (M-1, M- 5, M-7, M- 9, M-16, M-24, M- 26, M-27, M-28, M-31, M32, M- 34, M-36, M-37, M-41, M-52, M- 56, M-71, M-72) merdiven sayısı beş veya yedi olan tek sayılardan oluşur. Merdivensiz Dromoslar ise (M- 4, M- 10, M38, M-53) eğilimli bir rampa şeklinde mezar kapısına ulaşmaktadır. Dromoslu merdivenli mezarların tümünde, merdivenden inildikten sonra son basamakla kapı arasında bir boşluk bulunmaktadır. Bu boşluk kapının açılıp kapanmasına imkan sağlamak için bırakılmıştır. Tüm Dromoslu mezarların kapıları, genelde bir insanın ancak geçebileceği kadar, ortalama $0.60 \mathrm{~m}$. $-0.70 \mathrm{~m}$. civarındadır. Kapı kenarındaki duvar kalınlığı ortalama $0.50-0.90 \mathrm{~m}$. arasındadır. Kapılar, ya devrilerek açlıp kapanan Monoblok bir taş levha ya da, sağ veya sol kenara açılmış bir yuva (M-1, M- 24, M-27, M-38) içinde dik olarak hareket eden değirmen taş1 biçiminde yassı ve silindirik Monoblok bir kapak taşıdır. Kapıdan geçilip, mezar odasına girildiğinde, kapı eşiğine kıyasla oda tabanı yaklaşık olarak $0.40-0.60 \mathrm{~m}$. daha derinde yapılmıştır. Odaya inmek için bir adet basamak bırakılmıştır. Mezarların hepsinde giriş kapısının olduğu duvar hariç diğer dört duvarda, ölülerin konduğu üzeri kemerli niş olarak adlandırılan Arcaseliumlar yer almaktadır. Arcaseliumların her iki kenarlarında kalan boşluklar birbirlerine eşittir. Arcaseliumlar genellikle dairesel kemerli biçimler gösterirlerse de, bir örnekte (M24) beşik çatılı ve sivri kemerlidir. Arcaseliumların tabanı, mezar tabanından yaklaşık $0.90 \mathrm{~m}-1.00 \mathrm{~m}-1.10 \mathrm{~m}$. yüksekliktedir. Arcaseliumların uzunluğu ise 
$1.80 \mathrm{~m} .-2.20 \mathrm{~m}$. arasında, derinliği ise $0.80 \mathrm{~m} .-1.10 \mathrm{~m}$. arasında değişmektedir. M-72 ve M-72 nolu mezarların dromosları ortaktır ve merdivenlidir. M-5, M-27 ve M-31 nolu mezarlarda Bothros" denilen bir iskelet ve artık malzeme çukuru bulunmaktadir.

$\mathrm{Bu}$ gruba giren mezarlardan sadece M- 1, M-5, M-24, M-31 ve M-38 nolu mezarlar günümüze sağlam olarak koruna gelmiştir. Diğer mezarların ise, ya merdivenleri, ya kapıları ya da Arcaseliumları tahrip olmuştur.

\section{Basit girişli kaya mezarları}

Çoğunlukla doğal kayanın basamaklar meydana getirdiği yerlerde, cepheden kapı açılarak oyulan ve dış taraf ile neredeyse hemzemin olan mezarlardır (M-3, M-6, M-19, M-21, M-22, M-23, M- 29, M-63, M-67). Ana kayanın elverişli olmadığı bu mezarların girişleri basit olarak yapılmak zorunda kalınmıştır. Mezarların tümü tek odalı ve üç Arcaseliumludur. Bu mezarların kapı girişleri büyük monoblok taşla kapatılmış olmalıdır. Sadece M-6'da girişin solunda kap1 taşının yerleştirildiği kapı taşı yeri vardır. M-3'de mezar odası içerisinde solda zeminde kemiklerin konduğu bir çukur yer alır.

\section{Geçişli iki odalı mezarlar}

Kale eteği nekropolünde sadece iki mezar bu gruba girmektedir. $\mathrm{Bu}$ mezarlar (M-8, M-33) Dromosludur. M-8 de alt1 metrelik bir dromosdan sonra mezar kapısına ulaşılır. Dromos tamamen tahrip edilmiş zeminde derin çukur oluşmuştur. $0.70 \mathrm{~m}$. genişliğinde ve $1.10 \mathrm{~m}$. yüksekliğindeki kapı açıklığı ile öndeki mezar odasına girilir. Ön oda 3.10 x 3.40 m. ölçülerindedir. Sağ ve sol duvarda birer Arcaselium yer alır. Sağdaki Arcaselium tamamen tahrip olmuştur. Bu odanın tavanı tamamen çökmüş durumda üstü açıktır. Ön odadan, sivri kemerli beşik tonozlu bir kapı ile diğer odaya geçilir. Kapı, oldukça kalın bir kenara sahiptir. Bu oda 3.10 x 2.80 m. ölçülerindedir. Üç duvarda da Arcaselium bulunur. Sol ve karş1 duvardaki Arcaseliumlar tamamen tahrip olmuştur. Ön oda, kapı ve mezar odası aynı aks üzerine yapılmış ve simetriye çok dikkat edilmiştir. M-33 ise, geniş bir Dromosdan sonra ön mezar odası kapı girişine ulaşı1ır. Dromosun genişliği mezar odalarının genişliği kadardır. Ön odada sağ ve sol duvarda Arcaselium vardır. Ön odanın kapısı tamamen tahrip olmuştur. Girişte sağda kemik çukuru yer alır. Ön odanın tavanı çöktüğü için üzerin açıktır. Kemerli bir kapı ile ana mezar odasına girilir. Kapı eşiği ön mezar odasının zemininden $0.60 \mathrm{~m}$. yüksekte yapılmıştır. Ana oda 2.80 x $2.80 \mathrm{~m}$. ölçülerinde kare planlıdır.

\section{Loculuslu kaya mezarları}

Mezar odasının içinde dikine derin dikdörtgen hücrelere Loculus denmektedir. Bu tip mezarlarda ortak özellik kare ya da dikdörtgen biçimli orta mekanın üç kenarından yanlara, duvarların içine doğru dörtgen kesitli derin hücrelerin (Loculus) açılmış olmasıdır. Kale eteği nekropolünde M-11, M-17, M20, M-43, M-54, M-59 ve 59-A nolu mezarlar bu grub içerisinde yer alır. M-43 nolu Loculuslu mezar Nekopolün en tepe noktasında yer alır ve yakınında kaya mezarı yoktur. Yedi basamaklı Dromosdan sonra mezar kapısına ulaş1ır. Son basamak ile mezar kapısı arasında $2.20 \mathrm{~m}$. düz bir alan yer alır. Kapı genişliği 0.80 
m. derinliği $0.65 \mathrm{~m}$. ve yüksekliği $2.80 \mathrm{~m}$. dir. İki basamakla mezar odası girilir. İlk basamak mezar odasının dört yanını dolaşmaktadır. Mezar odası, 4.50 x $4.50 \mathrm{~m}$. ölçülerinde kara planlıdır. Yüksekliği ise, $3.90 \mathrm{~m}$. dir. Giriş kapısının hemen sağında ve solunda içerde birer Loculus, sağ duvarda dört, sol duvarda dört, karş1 duvarda ise köşelerde birer Loculus yer alır. Karşı duvarda tam ortada $2.85 \mathrm{~m}$. uzunlukta, $2.10 \mathrm{~m}$. genişlikte bir oda yer alır. Bu odanın hemen sağında bir oda daha yer alır. $\mathrm{Bu}$ oda, $4.30 \mathrm{~m}$. genişliğinde ve $2.20 \mathrm{~m}$. uzunluğundadır. Bütün Loculusların uzunluğu $2.20 \mathrm{~m}$. genişliği $0.70 \mathrm{~m}$. ve yüksekliği de $1.50 \mathrm{~m}$. dir. Her Loculus üzerinde $0.50 \mathrm{~m}$. uzunluğunda, $0.45 \mathrm{~m}$. genişliğinde ve $0.60 \mathrm{~m}$. yüksekliğe sahip birer niş bulunmaktadır. M-59 nolu mezar, $2.80 \mathrm{~m}$. uzunluğundaki bir Dromosdan sonra mezar kapısına ulaşılır. Kapı tamamen tahrip edilmiştir. Mezar odası $4.45 \mathrm{~m}$ x $2.20 \mathrm{~m}$. ölçülerindedir. Kapı karşısındaki duvarda iki Loculus yer alır. Loculuslar $2.10 \mathrm{~m}$. uzunluğunda, $0.80 \mathrm{~m}$. genişliğinde ve $1.40 \mathrm{~m}$. yüksekliğindedir. M-59 A nolu mezar ise, $3.00 \mathrm{~m}$. uzunluğundaki Dromostan sonra mezar kapısına ulaşılır. Kap1 $1.20 \mathrm{~m}$. yüksekliğinde, $0.65 \mathrm{~m}$. genişliğinde ve 0.50 m. derinliğindedir. Mezar odas 2.60 x $2.70 \mathrm{~m}$. ölçülerindedir. Sağ duvarda iki, sol duvarda üç ve karşı duvarda üç tane olmak üzere sekiz Loculus yer alır.

\section{Kaya Mezarları Taban Mozaikleri ve Freskler}

30 nolu mezar odas 2.87 x $2.80 \mathrm{~m}$. ölçüsünde ve $2.35 \mathrm{~m}$. yüksekliğindedir. İki Arcaseliumda 1slak sıva üzerine yapılan fresk yer alır. Güney Arcaseliumda, her iki kenarında simetrik olarak kaideli yivli tamburlu, Kompozit Korint başlıklı sütun tasvirleri bulunur. Arcaselium lahitinin dış yüzünde dikdörtgen panoda beyaz zeminde tabula antasa (kitabelik) tutan iki kadın betimi vardır. İçinde sekiz satırlı Yunanca yazıt yer alır. Kuzey Arcaselium lahtinin dış yüzünde de beyaz zeminde içinde dört satırlı Yunanca yazıt bulunan dikdörtgen biçimli tabula antasa tasviri bulunur. Yazıtlardan anlaşıldığına göre bu Fresk, Doksa Aile Kaya Mezarı'nın Fresk'idir (Önal 2017, 122-123).

65 nolu mezarın taban mozaiği. Ölçüleri, 2.85-2.64 x 2.72-2.56 m. dir. Mozaik geometrik desenlidir. Siyah bir bandın çevrelediği kare pano içerisinde beyaz zeminde siyah harflerle üç satır Estrangelo Süryanice yazıt yer alır. Yazıt, yazı biçimi ve şekline göre M.S. 3. yüzyılın 2. Yarısına tarihlendirilmektedir. Yazıttan anlaşıldığına göre bu mozaik, Abdu Ailesi Mozaği'dir (Önal 2017, 119).

67 nolu mezarın taban mozaiği. Mezar odası $2.62 \times 2.92 \mathrm{~m}$, mozaik panosu ise, 1.68 x $1.68 \mathrm{~m}$. ölçüsündedir. Mozaik geometrik desenli ve yazıtlıdır. Düz siyah çizgiyle çerçevelenen dikdörtgen panonun merkezinde etrafinda simetrik dört iri iğ hacı deseni bulunan bir çelen yer alır. Haçın etrafında Süryanice bir yazıt yer alır. $\mathrm{Bu}$ mozaik Hristiyan izlerinin görüldügü en erken mozaikler biri olması nedeniyle önemlidir (Resim 6).

69 nolu mezar odasının zemininde bir mozaik yer alır. Mezar odası $2.32 \mathrm{x}$ $2.22 \mathrm{~m}$, mozaik panosu da 1.29 x $1.18 \mathrm{~m}$. ölçüsündedir. Siyah bantla çerçevelenen kare panoda, ikisi üstte ikisi altta olmak üzere cepheden dört büst yer alır. Düz siyah çizgiyle çerçevelenen beyaz fondaki ikisi erkek ikisi kadın büstü yer alır. Figürlerin adları sağ yanlarına Estrangelo Süryanice yazıyla yazıldır. Panoda üst solda evin 
reisi ve mezar sahibi Gadya'nın büstü görülür. Gadya'nın sol yanında eşi Amma vardır. Alt sol çerçevede, Gadya'nın oğlu Aftua'nın büstü, Aftua'nın solunda ise Magdal yer alır. Yazıtlardan anlaşıldığına göre bu mozaik, Gadya Ailesi Mozaği'dir. Mozaik M.S. 3. yüzyılın başlarına tarihlendirilir. (Resim 7)

\section{Değerlendirme ve Sonuç}

Kale Eteği Nekropolündeki tüm mezarlar ana kayaya oyularak yapılmıştır. Mezar odasının iç düzenlemesinde farklılık olsa da mezarların ikisi hariç tümü tek odalıdır. İnançlar doğrultusunda kaya ve kayalıklar, yükseklik, ihtişam ve görkem açısından önemliydiler. Kayanın sağlamlığı ve kalıcı gücünün ölüleri sonsuzluğa götürmede önemli rolü olduğuna inanılırdı. Bu nedenle ölüyü kaya içinde saklamak isteği, mezar odaları yapılması ihtiyacı doğurmuştur. Genellikle eğimli bir yamaçta yer altına oyulmuş ve merdivenle inilen Dromoslara sahip mezarlar yapılmıştır. Bu mezar geleneğine uygun olarak, Şanlıurfa Kale eteğindeki tüm mezarların mezar odası plan olarak giriş, kapı ve iç mekandan oluşmaktadır. Mezar odası, içinde ölüleri saklayan yarı kutsal ve öteki dünya ile ilişkili bir mekan, giriş, insani mezar odasına doğru yönlendiren bir koridor olan Dromos ve kapı ise, her iki dünyay1 birbirine bağlayan bir geçittir. Yer altına yapılan bütün kaya mezar odalarında giriş için bir koridora ihtiyaç duyulmuş bunun sonucu olarak da Dromoslar ortaya çıkmıştır. Dromoslar, yer altı mezar odalarının oyulabilmesi için gerekli olan çalışma yerini sağlayan mimari öğeler olarak dikkat çeker. Son Tunç Çağında Batı Anadolu'daki Müskebi Nekropolünde (Özgünel 1987, 535), Gedikli ve Kırışkal Höyükdeki yer altı mezarlarında (Orthmann 1979, 101), Burdur / Kibyra'da (Başer 1990, 235) M. Ö. VI. yy'a tarihlenen mezarlarda, Kelenderis (Gilindere - Aydıncık) Nekropolünde (Zoroğlu 1994, 23-45) Dromoslu rampal1- basamaklı yer altı mezar odalarını görmekteyiz. Dromos bitiminde, bu koridoru mezar odasına bağlayan kapılar dikdörtgen planda yapılmıştır. Bu kapılar ya dikdörtgen biçimli Monoblok taş levha ile ya da silindir Monoblok taş ile kapatılmaktadır.

Kapıları düz kapak taşı veya silindirik taşlarla aç1lıp kapanan tek odalı ve 3-5 Arcaseliumlu oda mezarlarının orijinini, Erken Tunç Çağına kadar uzanan bir geçmişe sahip Kuzey Suriye'de yer alan mezarlarda görmekteyiz. Ölüyü mezar odasına koymanın bir varyasyonu olarak görülen Arcaseliumlar, Dağlık Kilikya'nın genelinde kaya mezarından anıt mezara kadar birçok mezar tipinde oldukça yaygın bir uygulamadır. Arcaselium, Termessos'da (Abbasoğlu 1987, 213), Çayönü Tepesi'nde (Çambel ve Braidwood 1980, 121), Kommagene'nin Besni Nekropolünde (Zeyrek 2007, 811vd, Res. 11), Tuğlu resimli kaya mezarlarında (Önal ve Güllüce 2004, 519vd, plan 1, Res. 1-28) mezar odasında vardır. Kommagene Bölgesi'nin özellikle Zeugma ve bölgenin Fırat boylarına özgü olan Roma etkili Arcaseliumları Kale Eteği Nekropolündeki mezarların hemen hemen hepsinde görmekteyiz (Wagner 1976, 147, Taf. 54). Kale Eteğinde bazı mezarlarda görülen Arcaselium derinliğinin içine yerleştirilen oygu tekneye yapılan gömü geleneğini, Dağlık Kilikya OLba-Diocaesarea Nekropollerinde (Er ve Söğüt 2005, 102) yaygın olarak görmekteyiz. Kemer nişlerin, üzerini kapadığı lahitlerden oluşan Arcaseliumlar, tek mezar odasının yan duvarlarına oyularak yapılmıştır. Yer altına 
yapılmış Dromoslu ve tek odalı mezarların yüzey kayasına da oyulduğu görülmektedir. İç düzenleme aynı olmakla birlikte bunların merdiven, Dromos veya doğrudan mezar odasına girişleri vardır. Çok odalı mezarlarda merkezi bir plan anlayışı olup, kapı girişinden itibaren ortada bir hol ve etrafinda buraya açılan duvarlarında Arcaseliumlar olan odalar yer almaktadır. Aydın Ballıkaya'da (Atalay 1987, 297), Eskişehir / Şükranlı Nekropolünde (Tokgöz 1976, 117-142), Eskişehir / Han ilçesinde (Pehlivaner ve Özçatal 1999, 67) çok odalı kaya mezarları görülmektedir. Hatay Reyhanlı'da Geç Roma dönemine birkaç odalı kaya mezarları görülür (Yenisoğac1 1990, 215).

Loculuslu mezarlarda ortak özellik, genelde Dromoslu merdivenli ya da basit girişlerden sonra kare yada dikdörtgen biçimli orta mekanın üç kenarından yanlara, duvar içine doğru dörtgen kesitli derin hücrelerin (Loculus) açılmış olmasıdır. Loculus tavanları, ceset yerleştirme işleminin kolayca yapılabileceği yüksekliktedir. Loculusların uzunluğu $2.10 \mathrm{~m}$. ve $2.20 \mathrm{~m}$. arasında, genişliği $0.70 \mathrm{~m}$. ve $0.80 \mathrm{~m}$. arasında ve yüksekliği de $1.50 \mathrm{~m}$. dir. Ancak M-59 nolu mezarda bu ölçüler daha azdır. Bu da bize M-59 un bir çocuk mezarı olduğunu göstermektedir. Loculusların tabanları düzdür. Loculuslu mezarlar içinde birçok ölünün yattığı mezar odalarıdır. $\mathrm{Bu}$ tip kaya mezarlarını Suriye'de özellikle Palmira'da görmekteyiz (Toynbee 1971,229vd, fig. 26-28).

\section{Tarihlendirme}

Kaya mezarlarını tarihlendirmek oldukça zordur. Mezar odalarının, birbirini takip eden kültürler tarafindan, bir çok kereler kullanılmış olması ve her seferinde de yeni bir amaçla bir öncesinin izlerini yok ederek bazı düzeltmelerin yapılması bu zorluğun en önemli nedenir. Mimari döşemler ve mezarlar içerisindeki buluntular sayesinde tarihlendirme yapılabilmek daha kolaydır. Kale Eteği Nekropolünde iki mezarın tabanında yer alan mozaikler bize tarihlendirmede yardımcı olmaktadır. Mezarın birindeki mozaiğin yazıtındaki, yazı biçimi ve şekline göre M.S. 3. yüzyılın 2. yarısına tarihlendirilmektedir. Diğer mezardaki mozaik ise M.S. 3. yüzyılın başlarına tarihlendirilir.

\section{KAYNAKÇA}

ABBASOĞLU, H. (1987), "1986 Y11ı Termessos Yüzey Araştırmaları" Arş. ST., No. 13, 203-215.

ATALAY, A. (1987), "İzmir ve Aydın Yörelerinde Mağara Araştırmaları" Arş. ST V-II., 290-301.

BAŞER, S. (1990) "1988-1989 Y1lları Kibyra Kurtarma Kazıları" Mz. KK. Sm. I., 232-245.

CORCMACK, S. (1997) "Funerary Monuments and Mortuary Practise in Roman Asia Minor" The Early Roman Empire in the East, (Ed.) Susan Alcock, Oxbow Monographies, Oxford. 
ÇAMBEL, H. ve R. BRAİDWOOD (1980) Güneydoğu Anadolu Tarih Öncesi Araştırmaları, İstanbul.

ÇEVIK, N. (2000) Urartu Kaya Mezarları ve Ölü Gömme Gelenekleri, T.T.K. Ankara.

ENSERT, K. (1995) Erken Tunç Çağı Güneydoğu Anadolu ve Kuzey Suriye Bölgesi Ölü Gömme Gelenekleri Işlğında Oylum Höyük Mezarları, (Hacettepe Üniversitesi Yayınlanmamış Doktora Tezi).

ER, Y. ve B. SÖĞÜT (2005) "Dağlı Kilikya'da Olba-Diocaesarea Nekropollerindeki Kaya Mezarları", TürkAD 5, 100-120.

IŞIK, F. (1989) "Batı Uygarlığının Kökeni, Erken Demirçağ Doğu-Batı Kültür ve Sanat İlişkilerinde Anadolu", Türk AD 28, 15-28.

KOCH, G. (2001) Roma Imparatorluk Dönemi Lahitleri, Arkeoloji ve Sanat Yayınları, İstanbul.

KURTZ, D. ve J. BOARDMAN (1971) Greek Burial Customs, New York, 1971.

MANSEL, A.M. (1971) “Gemlik Tümülüs Mezarı”, Belleten XXXVIII, Sayı 150, 540-560.

ORTHMANN, W. (1979) "Burial Customs of the III rd Millenium B.C. in Euphrates Valley" Le Moyen Euphrate, Strasbourg.

ÖNAL, M. (2017) Urfa-Edessa Mozaikleri, Şanlıurfa Büyükşehir Belediyesi Kültür ve Sosyal İşler Daire Başkanlığı, Aycı Promosyon Ltd. Şti., Zonguldak.

ÖNAL, M., H. GÜLLÜCE ve H. TUĞLU (2004) "Resimli Kaya Mezarı" 60. Yaşında Fahri Işılk'a Armağan, Anadolu'da Doğdu, İstanbul, 2004.

ÖZGÜÇ, T (1948) Ön Tarihte Anadolu'da Ölü Gömme Adetleri, Türk Tarih Kurumu, Ankara.

ÖZGÜNEL, C. (1987) "Selçuk Arkeoloji Müzesinde Saklanan Bir Myken Pyxis'i ve Düşündürdükleri”, Belleten LI sa. 200, 530-540.

PEHLIVANER, M. ve M.F. ÖZÇATAL (1994) "Yazılıkaya ve Han'da Kazı ve Temizlik Çalışmaları" 5. MKKS. 65-78.

SEEHER, J. (1993), Tarih Öncesi Çağlarda Ölüm ve Gömü, Arkeoloji ve Sanat Yayınları, İstanbul.

SiVAS, T. (1999) Eskişehir-Afyonkarahisar-Kütahya İ Sinırları İçindeki Phryg Kaya Anttlarl, Anadolu Üniversitesi Yayınları, Eskişehir.

TOKGÖZ, D. (1976) "Şükranlı Nekropol Kazısı-1974”, TAD, C. XXIII, No:2, 117-142.

TOYNBEE, J.M.C. (1971) Death and Burial in the Roman World, Ithaca.

TURANİ, A. (1993) Sanat Terimleri Sözlügü̈, Remzi Kitabevi, İstanbul.

WAGNER, J. (1976) Seleukeia am Euphrat/Zeugma, Wiesbaden.

YENISOĞACI, H.V. (1990) "Reyhanl1-Esentepe Kaya Mezarları Kutarma Kazısı" Mz. K.K: Sm. I, 210-225. 
ZEYREK, T.H. (2007) "Besni Nekropollerinden Kaya Mezarları", Belkis Dinçol ve Ali Dinçol'a Armağan, Hazırlayanlar. M. Alparslan-M.D. Alparslan-H. Peker, İstanbul, 810-826.

ZOROĞLU, L. (1994) Kelenderis I, Ankara.

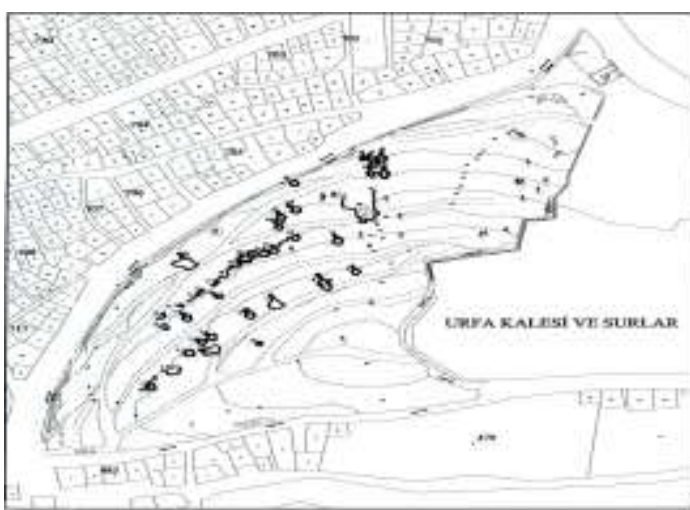

Resim 1 . Nekropoldeki konumlarl. Kaya mezarlarinin

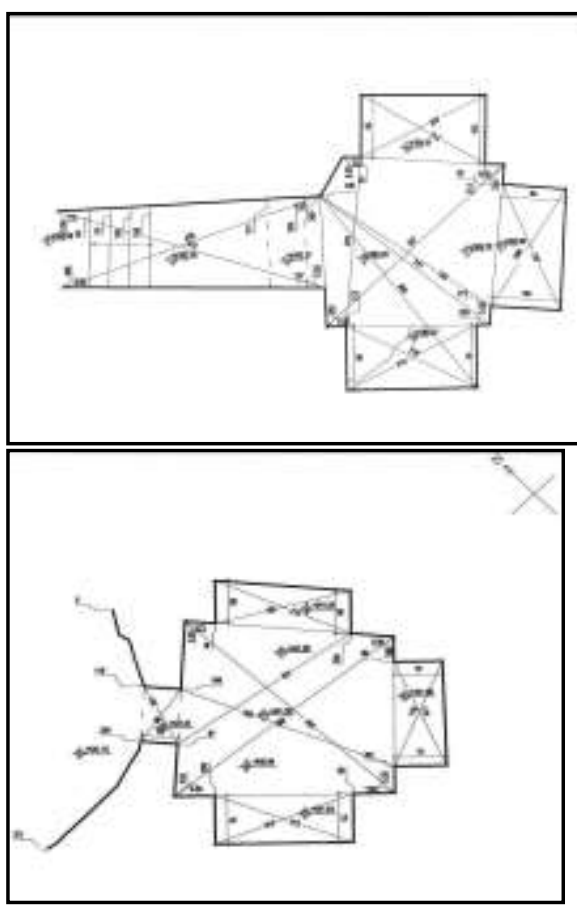

Resim 3. Dromoslu merdivenli, tek odall ve 3 Arcaseliumlu kaya mezarı planı.

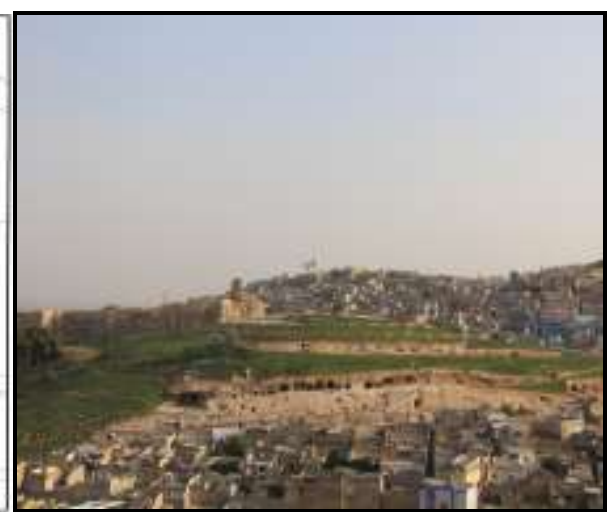

Resim 2. Kale Eteği Nekropolü.
Resim 4. Basit girisli tek odall ve 3 Arcaseliumlu kaya mezarl planı. 

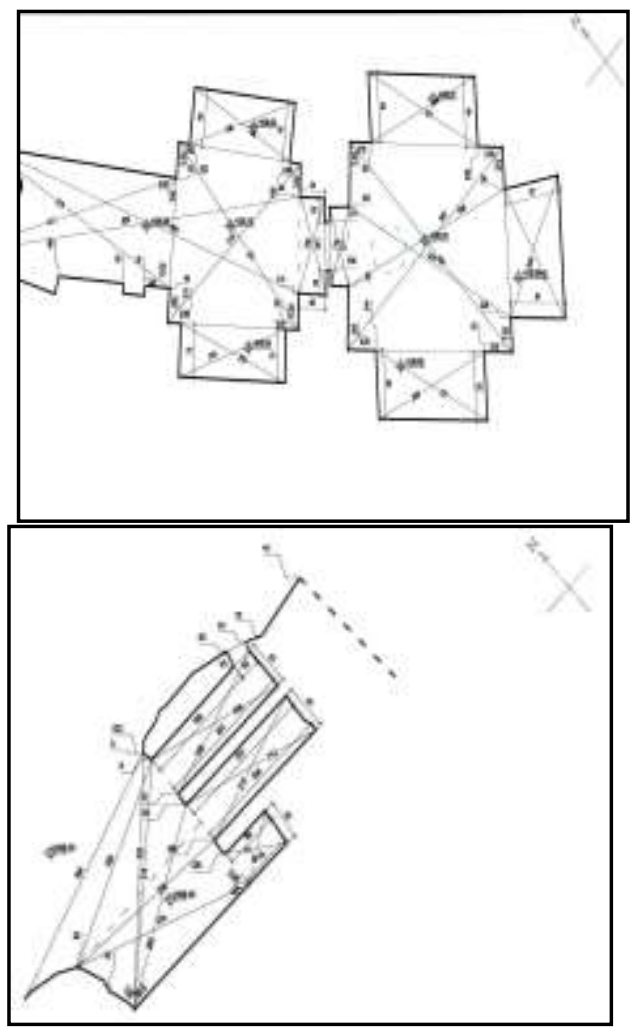

Resim 5. Dromoslu, geçişli iki odalı ve 5 Arcaseliumlu kaya mezarı planı.

Resim 6. Loculuslu kaya mezart planı. 


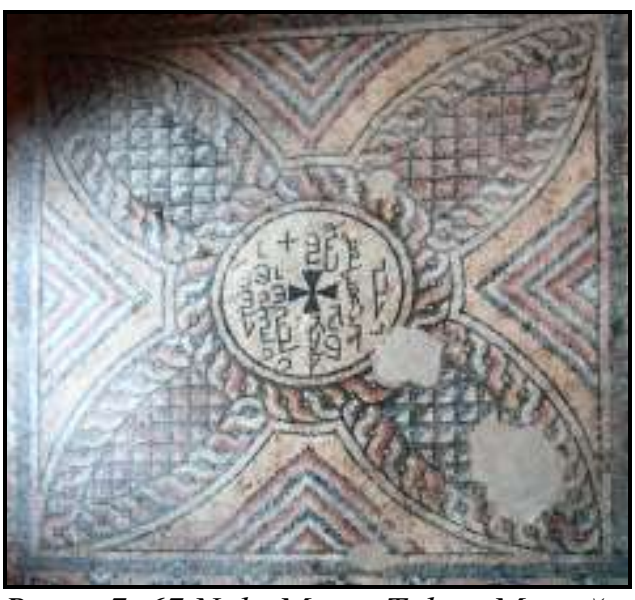

Resim 7. 67 Nolu Mezar Taban Mozaiği

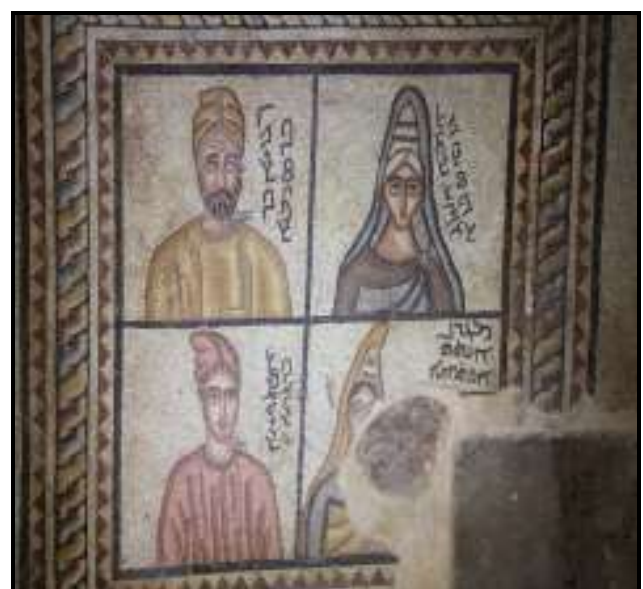

Resim 8. 69 nolu Mezar Odası Taban Mozaiği. Gayda Ailesi Mozaği 